upon the Lummis' observation must be found in the beariag, this has had upon the calculations of the great Paric astronomer. Always admiring the ingenious way in wite, Le Verrier attacked the problem, we are forced is the same time to find, that the pillars of his calculations, the data given by observation, upon closer examination have slipped away entirely. As a matter of course, the predictions of a re-appearance for Octobr. 1876 and for March 21-23. 1877, when the solar disk was subjected to the strictest scrutiny from all points of the world, had to fail.

\title{
Beobachtungen des Brorsen'schen Cometen und eines neuen Nebelflecks.
}

Wir haben hier so ungünstiges Wetter gehabt, dass ick den Brorsen'schen Cometen erst am 8. März mit Amici I auf einen Augenblick wieder sah; ich fand ibn in der Dämmerang, ohne dass ein Stern ringsum sichtbai' war, aber der Rand der Gallerie erlaubte nicht ihn weiter zu verfolgen. Daher versuchte ich am 10. Marz mit dem kleinen Fraunhofer in der Südwestlichen Kuppel einige Beobachtungen zu machen. Auch mit diesem Fernrohre war der Comet heller als die Vergleichsterne, die kaum zu erkennen waren, da sie im Dämmerungsscheine so nahe am Horizonte waren. Meine Beobachtungen - die noch der Correction für Refr. und Par. bedürfen, sind die folgenden:

\begin{tabular}{|c|c|c|c|c|c|c|c|}
\hline & Mittlere Zeit & $(\sqrt{3}$ & *) & $\Delta R$ app. & Decl. app. & A. d.V. & \\
\hline März 10 & $7 \mathrm{H} 2 \mathrm{~m} 59 \mathrm{~s}$ & $20 \div 87 \mid$ & $421^{\prime \prime} 0$ & 882 & $31^{\prime} 38^{\prime \prime} \tilde{0}$ & 2.0 & 1 \\
\hline 10 & T. 43.4 . & $-1 \mathrm{~m} 8.25$ & $\begin{array}{r}-0.22 .7 \\
-0\end{array}$ & $1.2 \times .32 .74$ & -0.31 .7 .7 & 1.1 & \\
\hline 14 & T.11.21. & -0.24 .00 & -10.14 .3 & 1.41 .46 .54 & +2.54 .40 .6 & 4.0 & 3 \\
\hline$\because 14$ & 7.35 .56 & +2.9 .23 & +6.52 .2 & 1.41 .49 .20 & +2.55 .37 .9 & 2.3 & $*_{4}$ \\
\hline
\end{tabular}

Dit scheinbaren Oerter der Vergleichsterne für die Beobachtungstage sind:

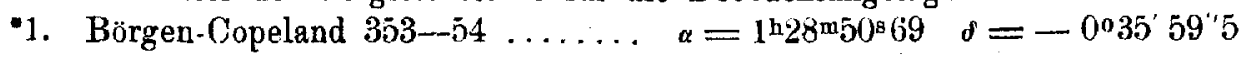

2. Weisse, I $491 \ldots \ldots \ldots \ldots \ldots \ldots . . \quad \alpha=1.29 .40 .99 \quad \delta=-0.30 .45 .0$

*3. Schjellerup $530 \quad \ldots \ldots \ldots \ldots \ldots, \alpha=1.42 .10 .54 \quad \delta=+3.4 .54 .9$

*4. Lalande $3230-31 \ldots \ldots \ldots \ldots \ldots, \alpha=1.39 .39 .97 \quad \delta=+2.48 .45 .7$

Am 14. März fand ich nahe bei den 4 Nebeln, über $15-20^{\prime \prime}$ von einander entfernt sind. Die Position für die ich in Nr. 2212. S. 51 und 52 einige Notizen gab, $-1879,0$ ist: $\alpha=11^{\mathrm{h}} 18^{\mathrm{m}} \overline{0}^{\mathrm{s}} \delta=+3058^{\prime} 36^{\prime \prime}$. Der Herscheleinen neuen Nebel, den ich, bei dieser so gut durch- sche Nebel II 32 war an beiden Abenden viel kleiner forschten Parthie, für einen schwachen Cometen hielt und schwacher als dieser neue Nebel, also ein auffalund deshalb sogleich eine Vergleichung mit *Weisse, I, lendes Object.

305 machte, aber erst am 16. März mich überzeugte, Arcetri bei Florenz, März 23, 1879. dass er fest stand. Es ist diess eigentlich ein feiner Doppelnebel mit zwei deutlichen Kernchen, die gegen

Will. Tempel.

\section{Vorläufige Anzeige über das Spectrum des Brorsen'schen Cometen.}

Wegen anhaltend trüben Wetters habe ich den Cometen erst am 18. März aufsuchen können. Er ist sehr hell und zeigt in der Mitte eine sehr starke Condensation. Er ist auch im Sucher des 6zölligen Merz'schen Refractors gut zu sehen. Es war mir nicht möglich, ihn mit einer starken Vergrösserung zu betrachten, da or schon dem Horizonte, der stark dunstig war, sehr nahe stand.

Zur spectroscopischen Beobachtung habe ich mich eines Amici'schen Prismas. in Verbindung des 6zöll. Merz'schen Refractors bedient, und zwar ohne Spalte.

Das Spectrum, welches genügend hell war, bestand aus 3 hellen Linien, worunter die mittlere die hellste war, jene dem brechenden Ende des Spectrums zu gelegene die schwächste.

Des tiefen Standes wegen war ich nicht im Stande, mehr Messungen an deu Linien anzustellen, wozu jedenfalls eine Spalte nothwendig gewesen wäre. Ich dachte die Messungen am folgenden Tage anzustellen, jedoch ist es leider seitdem immer bewölkt.

O Gyalla-Sternwarte 1879, den 20. Marz. voin Konkoly 